\title{
A dynamic model of the transport and logistics chain under conditions of interstate confrontation
}

\author{
A. O. Zhukov ${ }^{1,2,3,4}$, I. N. Kartsan ${ }^{1,5,6,7 *}$ A. G. Kharlamov ${ }^{1}$, A. I. Bashkatov ${ }^{1}$, S. \\ A. Razzhivaykin ${ }^{1}$, M.R. Razinkova ${ }^{1}$, V.O. Skripachev ${ }^{1}$ \\ ${ }^{1}$ FGBNU "Expert and Analytical Center", Talalikhina Str., 33, Building 4, Moscow, Russia \\ ${ }^{2}$ Joint Stock Company "Special Research of Moscow Power Engineering Institute", 14 \\ Krasnokazarmennaya Str., Moscow, Russia \\ ${ }^{3}$ MIREA - Russian Technological University, 78, Vernadskogo Av., Moscow, Russia \\ ${ }^{4}$ Institute of Astronomy of the Russian Academy of Sciences, 48, Pyatnitskaya Str., Moscow, \\ Russia \\ ${ }^{5}$ Marine Hydrophysical Institute, Russian Academy of Sciences», 2, Kapitanskaya Str., \\ Sevastopol, Russia \\ ${ }^{6}$ Reshetnev Siberian State University of Science and Technology, 31, Krasnoyarsky Rabochy \\ Av., Krasnoyarsk, Russia \\ ${ }^{7}$ Sevastopol State University, University Str. 33, Sevastopol, Russia \\ *E-mail: kartsan2003@mail.ru
}

\begin{abstract}
In this paper, it is proposed to assess the effectiveness of the logistics support system under given conditions of interstate confrontation with the use of non-military methods of coercive pressure, taking into account the set of macroeconomic parameters of socio-economic development of the state. This will make it possible to assess the effectiveness of production and transport and logistics chains at the system level, taking into account changes in the basic parameters that characterize the socio-economic development of the state.
\end{abstract}

Keywords: transport logistics, sanctions, dynamic model, material flow optimization 


\title{
Динамическая модель транспортно-логистикой цепочки в условиях межгосударственной конфронтации
}

\author{
А. О. Жуков ${ }^{1,2,3,4}$, И. Н. Карцан ${ }^{1,5,6,7 *}$, А. Г. Харламов ${ }^{1}$, А. И. Башкатов ${ }^{1}$, \\ С. А. Разживайкин ${ }^{1}$, М. Р. Разинькова ${ }^{1}$, В. О. Скрипачев ${ }^{1}$ \\ ${ }^{1}$ ФГБНУ «Экспертно-аналитический центр», ул. Талалихина, 33/4, г. Москва, \\ Российская Федерация \\ ${ }^{2} \mathrm{AO}$ «ОКБ МЭИ», ул. Красноказарменная, 14, г. Москва, Российская Федерация \\ ${ }^{3}$ ФББОУ ВО «МИРЭА - Российский технологический университет», ул. Вернадского, \\ 78 , г. Москва, Российская Федерация \\ ${ }^{4}$ ФГБУН «Институт астрономии Российской академии наук», ул. Пятницкая, 48, г. \\ Москва, Российская Федерация \\ ${ }^{5}$ ФББУН ФИЦ «Морской гидрофизический институт РАН ул. Капитанская, 2, г. \\ Севастополь, Российская Федерация \\ ${ }^{6}$ ФГБОУ ВО «Сибирский государственный университет науки и технологий имени \\ академика М.Ф. Решетнева», просп. им. газ. «Красноярский рабочий», 31, г. \\ Красноярск, Российская Федерация \\ ${ }^{7}$ ФГАОУ ВО «Севастопольский государственный университет», ул. Университетская, \\ 33, г. Севастополь, Российская Федерация \\ *E-mail: kartsan2003@mail.ru
}

\begin{abstract}
Аннотация. В данной работе оценку эффективности системы логистического обеспечения в заданных условиях межгосударственной конфронтации с использованием невоенных методов силового давления предложено осуществлять с учетом совокупности макроэкономических параметров социально-экономического развития государства. Это позволит на системном уровне оценить эффективность производственных и транспортно-логистических цепочек с учетом изменения базовых параметров, характеризующих социально-экономическое развитие государства.
\end{abstract}

Ключевые слова: транспортная логистика, санкции, динамическая модель, оптимизация материальных потоков

\section{1. Введение}

В современных условиях геополитических разногласий к России все чаще применяются невоенные методы воздействия, заключающиеся в санкционном ограничении, не только в части товарооборота, но и ограничения использования транспортных «артерий». Это обусловливает возникновение новых требований к существующей системе логистического обеспечения, требующих повышения ее эффективности в части оценки и прогнозирования производственных и транспортно-логистических цепочек в условиях межгосударственной конфронтации с использованием невоенных методов силового давления. 
Формирование эффективных логических систем в заданных условиях является одним из действенных инструментов повышения конкурентоспособности отраслей промышленности и экономики государства в целом. При этом необходимо подчеркнуть, что методологической основой в этих условиях является системный подход, принцип которого в концепции логистики поставлен на первое место. То есть научно-методический аппарат оценки эффективности производственных и транспортно-логистических цепочек в условиях межгосударственной конфронтации с использованием невоенных методов давления может быть реализован только при условии, если будет изложен точным и строгим научным языком.

Оценка эффективности системы логистического обеспечения в заданных условиях межгосударственной конфронтации с использованием невоенных методов силового давления предложено осуществлять с учетом совокупности макроэкономических параметров социально-экономического развития государства. Это позволит на системном уровне оценить эффективность производственных и транспортно-логистических цепочек с учетом изменения базовых параметров, характеризующих социально-экономическое развитие государства [1 -4].

\section{2. Построение модели}

Задача может быть решена реализацией двух последовательных этапов.

На первом этапе предлагается построение модели, позволяющей описать динамику производственных и транспортно-логистических цепочек относительно изменения базовых показателей социально-экономического развития. Это предложено реализовать через динамическую модель, позволяющую оценить эффективность, а также найти точки перелома (бифуркации) для максимизации задаваемых параметров [5]. Математическая формализация динамической модели в общем описании в виде, открытом для корректировки, сокращения, дополнения, представлена следующем образом:

$$
\left\{\begin{array}{l}
\frac{d x}{d t}=f\left(x, y, z, r, \lambda_{1} \ldots \lambda_{k}\right) \\
\frac{d y}{d t}=f\left(x, y, z, r, \lambda_{1} \ldots \lambda_{k}\right) \\
\frac{d z}{d t}=f\left(x, y, z, r, \lambda_{1} \ldots \lambda_{k}\right) \\
\cdots \\
\frac{d r}{d t}=f\left(x, y, z, r, \lambda_{1} \ldots \lambda_{k}\right) \\
x(0)=x_{0}, y(0)=y_{0}, z(0)=z_{0}, r(0)=r_{0}
\end{array}\right.
$$

где $x(t)$ - параметр, характеризующий социальную составляющую;

$y(t)$ - параметр, характеризующий экономическую составляющую;

$z(t)$ - параметр, характеризующий невоенные методы воздействия; 
$r(t)$ - параметр, характеризующий транспортно-логистическое обеспечение;

... - возможные дополнительные параметры;

$\lambda_{1} \ldots \lambda_{k}-$ параметры, для которых известны их пределы возможного изменения:

$$
\lambda_{j}^{\min } \leq \lambda_{j} \leq \lambda_{j}^{\max }, j=1, \ldots, k
$$

Моделирование, как метод приобретения информации о работе транспортнологистических цепочек в условиях межгосударственных конфронтаций с использованием невоенных методов силового давления, следует сравнить с математическим анализом и экспериментальным испытанием. При этом необходимо отметить, что анализ требует привлечения меньшего количества ресурсов, чем моделирование, которое, в свою очередь, требует меньшего объема ресурсов в сравнении с практическими испытаниями.

Моделирование занимает промежуточное положение между анализом и экспериментальным испытанием. Значение этих двух этапов проектирования не следует преуменьшать, так как они являются основой методического аппарата при проектировании систем. В настоящее время ни одна транспортно-логистическая система не создается без какого-либо моделирования, при этом хорошо выполненный проект (модель) системы будет применяться по мере необходимости.

На втором этапе предлагается решение оптимизационной задачи оценки эффективности производственных и транспортно-логистических цепочек в условиях межгосударственной конфронтации с использованием невоенных методов давления.

Предложено оценить максимально-допустимые расходы на транспортнологистическое обеспечение относительно социально-экономических возможностей государства. Задача состоит в выборе такого сочетания параметров $\lambda_{1} \ldots \lambda_{k}$, чтобы найти максимальное (при этом допустимое относительно других параметров) значение эффективности транспортно-логистических цепочек за рассматриваемый период, то есть найти максимальное значение величины за $n$ дней, недель, месяцев, лет:

$$
W=\sum_{i}^{n} w_{i}
$$

при условии неснижения задаваемых параметров, характеризующих развитие рассматриваемой системы:

$$
x_{i+1} \geq x_{i}, x_{i+1} \geq x_{i}, i=1, \ldots, n
$$

Нахождение максимума обусловлено жесткими условиями межгосударственной конфронтации с использованием невоенных методов силового давления (еще большие 
транспортно-логические расходы нерациональны с точки зрения социально-экономического развития), таким образом необходимо найти значение следующей величины:

$$
\max _{\lambda_{1} \ldots \lambda_{k}} F\left(\lambda_{1} \ldots \lambda_{k}\right)=\left(\sum_{i=1}^{n} w_{i} \prod_{i=1}^{n-1} \Theta\left(x_{i+1}-x_{i}\right) \prod_{i=1}^{n-1} \Theta\left(y_{i+1}-y_{i}\right) \prod_{i=1}^{n-1} \Theta\left(r_{i+1}-r_{i}\right)\right.
$$

где $\Theta(\mathrm{a})=\left\{\begin{array}{l}0,<0 \\ 1, \geq 0\end{array}\right.$ - единичная тета-функция Хевисайда, где $a\left(x_{i}, y_{i}, r_{i}\right)$ - решения системы дифференциальных уравнений в моменты времени $i=1, \ldots, n$.

Решение данной задачи в рассматриваемых условиях требует проведения самостоятельных объемных исследований. Ниже приведено краткое описание основных методических этапов.

Этапь методического подхода прогнозирования и очееки эффективности производственных и транспортно-логистических цепочек в заданных условиях.

Этап 1. Обоснование параметров оценки эффективности логистического обеспечения в заданных условиях. На данном этапе происходит обоснование параметров оценки эффективности логистического обеспечения посредством анализа значений эффективности логистических операций на макрологистическом уровне через оценку экономического эффекта, образуемого за счет:

снижения запасов до оптимального уровня на всех участках товародвижения;

сокращения времени товародвижения путем четкого планирования и организации отдельных этапов;

снижения транспортных расходов за счет более эффективного использования транспорта и поиска оптимальных схем товародвижения;

сокращения затрат ручного труда через исключение неэффективных и ненужных операций с грузами.

Этап 2. Подготовка исходных данных для оценки эффективности логистического обеспечения в условиях межгосударственной конфронтации с использованием невоенных методов силового давления. Подготовка исходных данных подразумевает необходимость проведения регрессионного анализа, необходимого для задания и прогнозирования тенденций развития параметров, характеризующих развитие логистического обеспечения в заданных условиях.

Этап 3. Анализ исходных данных, оценка их достаточности и корректности. На данном этапе происходит оценка достаточности и достоверности исходной информации, определение законов распределения. Выбор подхода для оценки достаточности зависит от используемого закона распределения. 
Этап 4. Корректировка исходных данных (привлечение экспертных заключений). Данный этап предполагает дополнение исходной информации посредством применения методов экспертного оценивания. Методическая составляющая данного этапа зависит от количества и квалификации привлекаемых экспертов [6 -8].

Этап 5. Обоснование корреляции базовых параметров социально-экономического и логистического развития государства. На данном этапе происходит обоснование корреляции рассматриваемых параметров для решения конкретной задачи.

Этап 6. Задание агрегированных параметров, характеризующих зависимость социально-экономического и логистического развития государства. На данном этапе проходит задание и обоснование агрегированных параметров.

Этап 7. Формализация и обоснование зависимостей социально-экономического и логистического развития государства. На данном этапе посредством математических преобразований, выявленных корреляций и обоснованных агрегированных коэффициентов происходит формализация зависимостей.

Этап 8. Моделирование социально-экономического и логистического развития государства в заданных условиях. Моделирование в данном случае сводится к интегрированию полученной системы дифференциальных уравнений.

Этап 9. Оценка и прогнозирование эффективности логистического развития государства. Оценка и прогнозирование эффективности производственных и транспортнологистических цепочек в условиях межгосударственной конфронтации с использованием невоенных методов силового давления предполагает применение классических методов оптимизации, зависящих от природы рассматриваемой модели.

Схематично данные этапы отражены на рисунке 1. При этом необходимо учитывать, что в процессе проведения исследований, могут появляться проблемные вопросы, требующие пересмотра уже отработанных этапов (на схеме не отражено).

Необходимо подчеркнуть, что идея решения задачи заключается в установлении корреляции основных параметров социально-экономического развития государства и эффективности транспортно-логистических цепочек за рассматриваемый период.

Реализация данных этапов предполагает проведение достаточно объемных исследований, сложность которых заключается в подготовке необходимой информации, зачастую находящейся в разных ведомствах. 


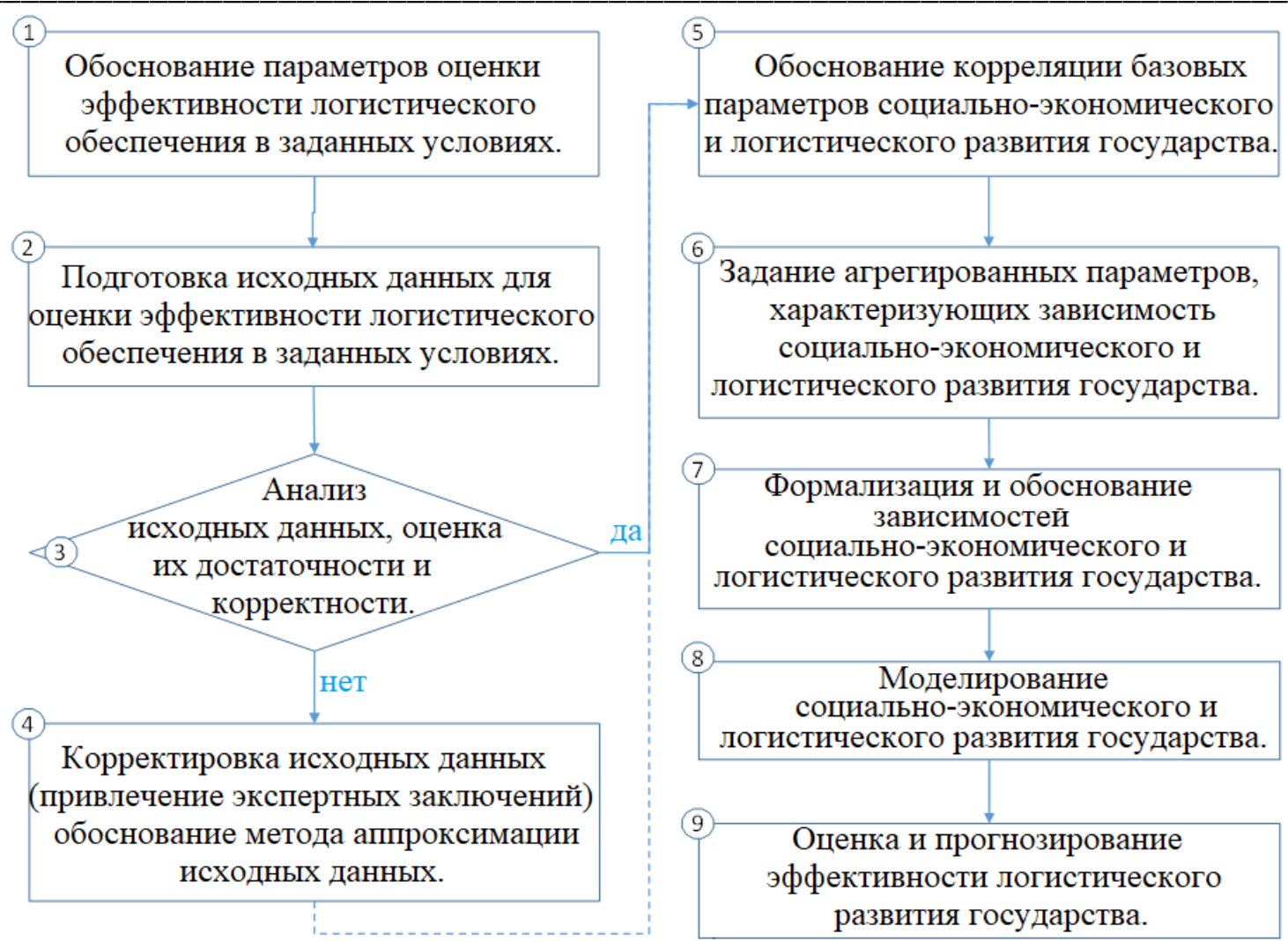

Рисунок 1. Схема методических этапов, предлагаемого инструментария.

Ее получение в корректном, применимом для анализа виде проблематично, требует дополнительных организационных мероприятий и согласований.

\section{3. Заключение}

Таким образом задача оптимизации материальных потоков на уровне государства в условиях межгосударственной конфронтации с использованием невоенных методов силового давления решается за два последовательных этапа. На первом этапе происходит построение модели, позволяющей описать динамику производственных и транспортно-логистических цепочек относительно изменения базовых показателей социально-экономического развития. На втором этапе происходит оценка максимально-допустимых расходов на транспортнологистическое обеспечение относительно социально-экономических возможностей государства.

\section{Благодарности}

Работа выполнена в рамках государственного задания Минобрнауки России по теме «Концептуальное моделирование информационно-образовательной среды воспроизводства человеческого капитала в условиях цифровой экономики» (Шифр FNRN - Е). Работа выполнена в рамках государственного задания Минобрнауки России по теме «Разработка новых методов автономной навигации космических аппаратов в космическом пространстве» 
(Шифр FNRN - S). Работа выполнена в рамках государственного задания по теме № 05552021-0005.

\section{Список литературы}

[1] Гуд, Г. Системотехника: введение в проектирование больших систем / Г. Гуд, Р. Маккол - М.: Советское радио, 1962. - 383 с.

[2] Маккол, Р. Справочник по системотехнике / Пер. с англ.; под ред. А.В. Шиленко. - М.: «Советское радио», 1970. - 688 с.

[3] Пестун, У.А. Управление социальной и экономической системами в условиях требуемого уровня обороноспособности / У.А. Пестун, А.О. Жуков. - М.: ФГБУН «Аналитический центр» Минобрнауки России, 2017. - 144 с.

[4] Жуков, А.О. Основы экспертного оценивания / А.О. Жуков, У.А. Пестун. - М.: ФГБУН «Аналитический центр» Минобрнауки России, 2017. - 65 с.

[5] Жуков, А.О. Стили руководства в современных группах и организациях / А.О. Жуков, И.А. Кобзев // Этносоциум и межнациональная культура. - 2008. - № 1(9). - С. 180185.

[6] Хемилтон, А. Инновационная и корпоративная реструктуризация в мировой экономике / А. Хемилтон // Проблемы теории и практики управления. - 2000. - № 6. - С. 37-39.

[7] Лукинский В.С. Модели и методы теории логистики. СПб.: Питер, 2003. - 176 с.

[8] Карасева, М.В. Метапоисковая мультилингвистическая система / М.В. Карасева, И.Н. Карцан, П.В. Зеленков // Вестник Сибирского государственного аэрокосмического университета им. академика М.Ф. Решетнева. - 2007. - № 316. - С. 69-70. 